Section Editor

Robert C. Griggs, MD
Editors' Note: Both articles discussed in this week's WriteClick posts note that uncontrolled epilepsy has serious consequences, both financial and to the patient's quality of life. Despite American Academy of Neurology (AAN) guidelines being in place, referrals to epilepsy surgery still lag. Authors Jette et al. have developed an easy-to-access, easy-to-use online tool to help guide clinicians considering referring their patients for surgery (www.epilepsycases.com). The clinician answers 8 objective questions, at the end of which the Web site suggests whether to refer or not. Fast, mobile, and with a format comfortable to the online generation, could this be a harbinger of the future for clinical guidelines?

Megan Alcauskas, MD, and Robert C. Griggs, MD

\section{DEVELOPMENT OF AN ONLINE TOOL TO DETERMINE APPROPRIATENESS FOR AN EPILEPSY SURGERY EVALUATION}

Marino M. Bianchin, Ana Lucia Abujamra, Porto

Alegre, Brazil: Jette et al. ${ }^{1}$ proposed a Web-based tool for referring patients for epilepsy surgery-an unsolved problem despite established AAN guidelines. ${ }^{2}$ The gap in epilepsy surgery referrals may be due to the uncertainty that physicians and patients have about surgical prognosis. Developing efficient presurgical predictive models from the results of epilepsy surgery would be helpful. Unfortunately, predictive models for surgical outcome in epilepsy have been rarely used, despite their potential impact in this field. Pinheiro-Martins et al. ${ }^{3}$ developed a predictive model for the surgical outcome of frontal lobe epilepsy with an accuracy of $80 \%$, which illustrates the potential these models possess in better informing patients and neurologists about surgical prognosis in refractory epilepsy. Eventually these models could also become useful for developing surgical protocols and procedures, allowing optimization of epilepsy surgery across several scenarios. Appropriate referral tools coupled with multicenter-validated predictive models for surgical outcome developed under modern investigative protocols may lead to optimal results in epilepsy surgery, ultimately maximizing the benefit for our patients. This would be epilepsy surgery at its best.
Author Response: Nathalie Jette, Hude Quan, Calgary; Jose Tellez-Zenteno, Saskatoon; Walter Hader, Samuel Wiebe, Calgary, Canada: We thank Drs. Bianchin and Abujamra for their interest in our Web-based tool to identify patients who may be candidates for an epilepsy surgery evaluation. ${ }^{1}$ It is important that any new tool incorporates the highest level of evidence. Although numerous cohort studies and some systematic reviews have examined predictors of epilepsy surgical success, clinical decision analysis models to guide epilepsy care are rare. Examples of such tools include those devised by Pinheiro-Martins et al. ${ }^{3}$ and Choi et al. ${ }^{4}$ The latter is an elegant decision analysis model that estimates the effect of anterior temporal lobe resection vs continued medical management on quality-adjusted life expectancy in patients with drug-resistant temporal lobe epilepsy. We concur with Bianchin and Abujamra that appropriate referral tools "coupled with multicenter-validated predictive models for surgical outcomes" may lead to better selection of patients and improved epilepsy surgical outcomes. It is vital to validate these tools and decision analysis models in different settings to ensure they are sufficiently sensitive and specific. Ideally, patient preference should also be incorporated into the decision-making process both for referral for presurgical evaluation and for surgical decision-making.

\section{2013 American Academy of Neurology}

1. Jette N, Quan H, Tellez-Zenteno JF, et al. Development of an online tool to determine appropriateness for an epilepsy surgery evaluation. Neurology 2012;79:10841093.

2. Engel J, Jr, Wiebe S, French J, et al. Practice parameter: temporal lobe and localized neocortical resections for epilepsy: report of the Quality Standards Subcommittee of the American Academy of Neurology, in association with the American Epilepsy Society and the American Association of Neurological Surgeons. Neurology 2003;60: 538-547.

3. Pinheiro-Martins AP, Bianchin MM, Velasco TR, et al. Independent predictors and a prognostic model for surgical outcome in refractory frontal lobe epilepsy. Epilepsy Res 2012;99:55-63

4. Choi H, Sell RL, Lenert L, et al. Epilepsy surgery for pharmacoresistant temporal lobe epilepsy: a decision analysis. JAMA 2008;399:2497-2505. 


\section{Neurology}

\section{Development of an online tool to determine appropriateness for an epilepsy surgery evaluation}

Marino M. Bianchin, Nathalie Jette, Ana Lucia Abujamra, et al. Neurology 2013;80;2169

DOI 10.1212/WNL.0b013e3182987a80

This information is current as of June 3, 2013

\section{Updated Information \&} Services

References

Permissions \& Licensing

Reprints including high resolution figures, can be found at: http://n.neurology.org/content/80/23/2169.full

This article cites 4 articles, 2 of which you can access for free at: http://n.neurology.org/content/80/23/2169.full\#ref-list-1

Information about reproducing this article in parts (figures,tables) or in its entirety can be found online at:

http://www.neurology.org/about/about_the_journal\#permissions

Information about ordering reprints can be found online: http://n.neurology.org/subscribers/advertise

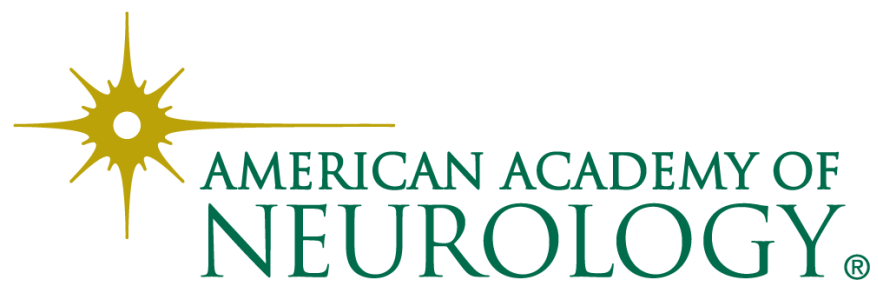

